Check for updates

Cite this: RSC Adv., 2018, 8, 39214

\title{
Facile synthesis of a flame retardant melamine phenylphosphate and its epoxy resin composites with simultaneously improved flame retardancy, smoke suppression and water resistance
}

\begin{abstract}
Yilun Shi, ${ }^{\text {Z }}$ Zhengzhou Wang (D) *ab and Jian-an Zhou ${ }^{\mathrm{c}}$
A flame retardant melamine phenylphosphate (MPhP) was facilely synthesized by the reaction of phenylphosphoric acid (PPA) and melamine (MEL), and was characterized by FTIR and NMR. Epoxy resin (EP) composites containing MPhP were prepared, and the effect of MPhP content on flame retardancy, smoke suppression, mechanical properties and thermal stability of the composites was investigated. It is observed that the LOI of the EP composite with 20 wt\% MPhP (EP/MPhP20) is $26.5 \%$, and the composite $\mathrm{EP} / \mathrm{MPhP} 20$ reaches a UL $94 \mathrm{~V}-0$ rating. Cone calorimeter test results show that the peak heat release rate, total heat release and total smoke release of EP/MPhP20 decrease by $51 \%$, $34 \%$, and $24 \%$, respectively compared with those of pure EP. The flame retardancy of the EP/MPhP composites after the water treatment at $80{ }^{\circ} \mathrm{C}$ for $72 \mathrm{~h}$ is basically maintained, indicating that the composites have good water resistance. The mechanical strengths of the EP/MPhP composites decrease gradually with an increase in the MPhP content. Moreover, the thermal stability of the EP/MPhP composites was studied.
\end{abstract}

Received 20th October 2018 Accepted 16th November 2018

DOI: $10.1039 / \mathrm{c} 8 \mathrm{ra0} 8696 f$

rsc.li/rsc-advances flame retardants, organic phosphonic acids and their derivatives are widely used in EP. For example, 9,10-dihydro-9-oxa10-phosphaphenanthrene-10-oxide (DOPO) is commonly used in EP because it has reactive $\mathrm{P}-\mathrm{H}$ bond, which can react with many kinds of groups including epoxide groups in EP. ${ }^{\mathbf{1 4 , 1 5}}$ For example, Perret et al. prepared DOPO-based flame retardants, DOPP and DOPI, and found that the LOI of the EP composites with $20 \mathrm{wt} \%$ DOPP and $23 \mathrm{wt} \%$ DOPI reach up to $37.9 \%$ and $34.2 \%$, respectively, and the peak heat release rate of the composites decrease by $31 \%$ and $49 \%$, respectively and total heat release $40 \%$ and $44 \%$, respectively, compared with the ones of pure EP resin. ${ }^{\mathbf{1 1}}$ It was reported that a flame retardant TGIC-DOPO prepared by the reaction of DOPO and triglycidyl isocyanurate (TGIC) had good flame retardancy, and the LOI of the EP composite with $10 \mathrm{wt} \%$ TGIC-DOPO reached to $35.2 \% .^{12}$ Zhang et al. observed that polyhedral oligomeric silsesquioxanes containing DOPO (DOPO-POSS) and octaphenyl polyhedral oligomeric silsesquioxane/DOPO (OPS/ DOPO) were effective flame retardants in EP, and the EP composite containing 2.5 wt\% DOPO-POSS and 1.1/1.8 wt\% OPS/DOPO can pass UL-94 V-0 test, with a LOI of $32.7 \%$ and $35 \%$, respectively. ${ }^{13}$

Ammonium polyphosphate (APP), a commonly used inorganic phosphorus- and nitrogen-containing compound, is also an effective flame retardant in EP. Wang et al. investigated the effect of APP on flame retardancy of low molecular weight polyamide (LWPA) cured epoxy resin (diglycidyl ether of bisphenol A), and found that the LOI values of the epoxy resins 
containing $15 \mathrm{wt} \%$ APP increased from $29.6 \%$ to $32.0 \%$ with a decrease in the content of LWPA from $28.3 \mathrm{wt} \%$ to $19.6 \mathrm{wt} \%$, but the FR cured epoxy resins all passed UL $94 \mathrm{~V}-0$ rating. ${ }^{16}$ Tan and co-workers prepared a piperazine-modified APP (PAz-APP) as a flame retardant hardener for EP, and they found that EP/ PAz-APP composites have much better flame retardancy than EP/Paz. ${ }^{17}$ Song et al. prepared EP composites containing APP and lanthanum trioxide $\left(\mathrm{La}_{2} \mathrm{O}_{3}\right)$, and their results show that the EP composite with $20 \mathrm{wt} \%$ of APP can reach UL $94 \mathrm{~V}-0$ rating and the addition of $\mathrm{La}_{2} \mathrm{O}_{3}$ in EP/APP composites led to formation of more compact char. ${ }^{18}$

Nevertheless, APP is easily attacked by water and exuded, which leads to in a decrease in the flame retardancy of its flame retarded polymer composites during their service life. ${ }^{19}$ In order to overcome this problem, Liu et al. used epoxy resin as a shell material to prepare microencapsulated APP (MCAPP), and found that the solubility of MCAPP in water at $25{ }^{\circ} \mathrm{C}$ and $80{ }^{\circ} \mathrm{C}$ was much lower than the one of APP, and that the water resistance and mechanical properties of the EP/MCAPP composites improved a lot in comparison with those of the EP/APP composites. $^{20}$ Tang et al. observed that APP microencapsulated with glycidyl methacrylate (GMA) improved its hydrophobicity and the flame retardancy of the EP composite containing the microencapsulated APP was better than the one of the EP/APP composite at the same additive content. ${ }^{21}$

In fact, flame retardants with lower water solubility, excellent flame retardancy and better compatibility with EP are anticipated. In this study, a phosphorus and nitrogen-containing flame retardant named melamine phenylphosphate (MPhP) was synthesized by the reaction of melamine and an organic phosphorus-containing acid, i.e. phenylphosphonic acid. The water resistance of MPhP was investigated through the test of solubility. The effect of MPhP on flame retardancy, mechanical properties, hot water resistance and thermal stability of epoxy resin was investigated in this work.

\section{Experimental}

\section{Materials}

Phenylphosphoric acid (PPA), analytical grade, was purchased from Sinopharm Chemical Reagent Co., Ltd. Melamine (MEL), analytical grade, was purchased from Anhui Hongsifang Co., Ltd. Epoxy resin (E-51) with an epoxy equivalent weight (EEW) of $186 \mathrm{~g}$ eq. ${ }^{-1}$, was purchased from Sinopec Group Company. Curing agent (T-31) was a commercial product with an amine value of $520 \mathrm{mg} \mathrm{KOH}$ per g. Defoamer (BYK-A530) was purchased from BYK Additives \& Instruments.

\section{Preparation of melamine phenylphosphate (MPhP)}

First, $32 \mathrm{~g}$ of phenylphosphoric acid (PPA) was added into a $1000 \mathrm{ml}$ three-necked flask equipped with a mechanical stirrer. Then $400 \mathrm{ml}$ deionized water was added and continuously stirred until the PPA was completely dissolved. After that, $25.5 \mathrm{~g}$ melamine (MEL) (the molar ratio of PPA/MEL $1: 1$ ) was added into the above mixture afterwards, the temperature of the resultant solution was raised to $95{ }^{\circ} \mathrm{C}$ and maintained at that

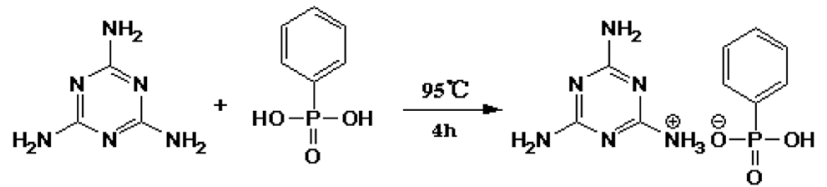

Fig. 1 Synthetic route of MPhP.

temperature for $4 \mathrm{~h}$. Finally, the resultant product was filtered, washed several times with hot deionized water and dried, and the white powder MPhP was obtained. The synthetic route of MPhP is shown in Fig. 1.

\section{Preparation of EP and the EP/MPhP composites}

To prepare the samples, EP was mixed with MPhP according to the formulations in Table 1 . And a defoamer $(0.5 \mathrm{wt} \%$ of the total amount of epoxy resin and curing agent) was added to EP. After being mixed uniformly, the mixture was thoroughly mixed with the curing agent T-31 (35 wt\% of the epoxy resin) and poured into polytetrafluoroethylene (PTFE) molds for curing. After curing for $1 \mathrm{~h}$ at $25^{\circ} \mathrm{C}$ and for $3 \mathrm{~h}$ at $70{ }^{\circ} \mathrm{C}$, MPhP-modified epoxy resin samples were obtained.

\section{Characterization}

Fourier transform infrared (FTIR) spectra were performed on a Hyperion 2000 instrument (Bruker Optics, Germany). The spectral range is $7500-370 \mathrm{~cm}^{-1}$, and resolution is less than $0.5 \mathrm{~cm}^{-1}$.

Nuclear magnetic resonance (NMR) analysis was measured by AVANCE III NMR instrument (Bruker, Switzerland) to detect phosphorus spectrum $\left({ }^{31} \mathrm{P} \mathrm{NMR}\right)$ of the samples which were dissolved in deuterated dimethyl sulfoxide ( $\mathrm{d}_{6}$-DMSO).

The limiting oxygen index (LOI) was measured with a sample dimension of $100 \times 6.5 \times 3 \mathrm{~mm}^{3}$ according to GB/T 2406-2009 standard.

Vertical burning tests (UL-94) were performed on a CZF-3 vertical combustion tester (Jiangning Analytical Instrument Factory, China) according to GB/T 2408-2008, and the sample dimension was $125 \times 13 \times 3 \mathrm{~mm}^{3}$.

Cone calorimeter (CC) tests were measured on a cone calorimeter (Fire Testing Technology) at a heat flux of $35 \mathrm{~kW} \mathrm{~m}^{-2}$ with a sample dimension of $100 \times 100 \times 3 \mathrm{~mm}^{3}$ according to ISO 5660 standard.

Table 1 Formulations of pure EP and the EP/MPhP composites

\begin{tabular}{llll}
\hline Sample code & EP $(w t \%)$ & Curing agent (wt $\%)$ & MPhP (wt\%) \\
\hline EP0 & 74.1 & 25.9 & 0 \\
EP/MPhP5 & 70.4 & 24.6 & 5.0 \\
EP/MPhP10 & 66.7 & 23.3 & 10.0 \\
EP/MPhP15 & 63.0 & 22.0 & 15.0 \\
EP/MPhP20 & 59.3 & 20.7 & 20.0 \\
EP/MPhP25 & 55.6 & 19.4 & 25.0
\end{tabular}


Thermogravimetric (TG) analysis was carried out on a STD Q600 thermal gravimetric analyzer (TA, USA) at a heating rate of $10{ }^{\circ} \mathrm{C} \min ^{-1}$ under nitrogen atmosphere.

Scanning electron microscopy (SEM) was conducted by S4800 instrument (Hitachi, Japan) to characterize the fracture surface morphology of pure EP and the EP/MPhP composites before and after boiling. The samples were previously coated with a conductive layer of gold.

The tensile strength was measured by CMT5105 universal testing machine with test part dimension of $80 \times 10 \times 4 \mathrm{~mm}^{3}$ according to GB/T 1040-2006 standard, and at least five samples were tested to get an average value. The impact strength was measured by SANS E21 pendulum impact testing machine with dimension of $80 \times 10 \times 4 \mathrm{~mm}^{3}$ according to GB/T 1043-2008 standard, and at least five samples were tested to get an average value.

\section{Results and discussion}

\section{Characterization of MPhP}

FTIR. The FTIR spectra of MEL, PPA and MPhP are presented in Fig. 2. Fig. 2a shows the FTIR of MEL. The peaks at $3469 \mathrm{~cm}^{-1}$ and $3423 \mathrm{~cm}^{-1}$ are attributed to the asymmetric and symmetric stretching vibration of $-\mathrm{NH}_{2}$ respectively, and the peaks at $3340 \mathrm{~cm}^{-1}$ and $3141 \mathrm{~cm}^{-1}$ correspond to the stretching vibration of $\mathrm{N}-\mathrm{H}$ with hydrogen bonds. ${ }^{22}$ The peak at $1655 \mathrm{~cm}^{-1}$ represents the deformation vibration of $\mathrm{N}-\mathrm{H}$. The peaks at $1556 \mathrm{~cm}^{-1}, 1440 \mathrm{~cm}^{-1}$ and $810 \mathrm{~cm}^{-1}$ are characteristic absorption peaks of triazine rings. ${ }^{23,24}$ The FTIR of PPA is shown in Fig. 2b. The wide peak at $3375 \mathrm{~cm}^{-1}$ corresponds to the stretching vibration of $\mathrm{O}-\mathrm{H}$. The peak at $1211 \mathrm{~cm}^{-1}$ is the stretching vibration of $\mathrm{P}=\mathrm{O}$, and the peaks at $1012 \mathrm{~cm}^{-1}$ and $911 \mathrm{~cm}^{-1}$ are attributed to the stretching vibration of $\mathrm{P}-\mathrm{O} .^{25-28}$ In addition, the peaks at $752 \mathrm{~cm}^{-1}$ and $714 \mathrm{~cm}^{-1}$ are the absorptions of $\mathrm{C}-\mathrm{H}$ on the phenyl rings. As for the FTIR of MPhP (Fig. 2c), the peaks at $3340 \mathrm{~cm}^{-1}$ and $3141 \mathrm{~cm}^{-1}$ attributed to the stretching vibration of $\mathrm{N}-\mathrm{H}$ with hydrogen bonds

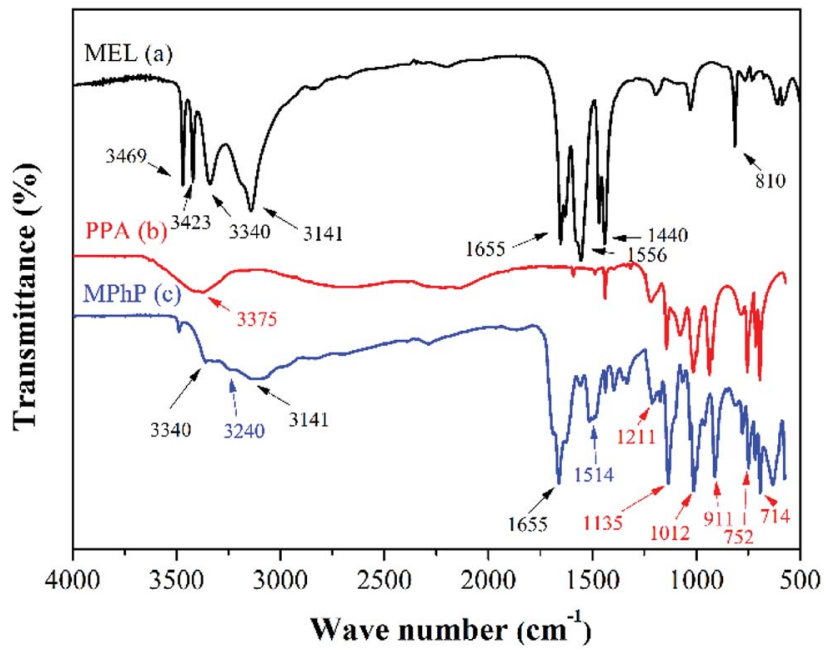

Fig. 2 FTIR spectra: (a) MEL; (b) PPA; (c) MPhP.

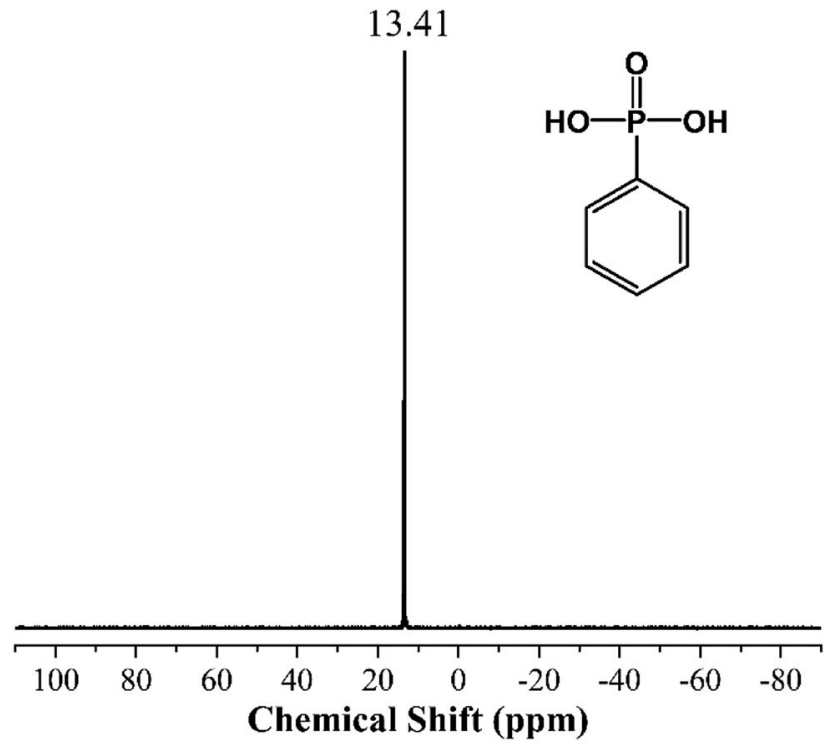

Fig. $3{ }^{31}$ P NMR of PPA.

still can be found. The peak at $1655 \mathrm{~cm}^{-1}$ attributed to the deformation vibration of $\mathrm{N}-\mathrm{H}$ still exists, and the typical absorptions from the triazine rings also exist. The disappearance of the peaks at $3469 \mathrm{~cm}^{-1}$ and $3423 \mathrm{~cm}^{-1}$ and the new adsorption peak at $3240 \mathrm{~cm}^{-1}$ indicate the formation of $\mathrm{NH}_{3}{ }^{+} \cdot{ }^{29,30}$

NMR. Fig. 3 and 4 show the ${ }^{31}$ P NMR of PPA and MPhP. It can be noted from Fig. 3 that PPA has only one strong peak (13.41 ppm). As for the ${ }^{31} \mathrm{P}$ NMR of MPhP (Fig. 4), there is only one peak at $11.62 \mathrm{ppm}$, which indicates that the phosphorus in MPhP has one chemical environment. The peak moves to a lower chemical shift because the density of electron clouds around the $\mathrm{P}$ nucleus in MPhP increases after the formation of salt compared with the one in PPA. ${ }^{31}$ The similar result was also found in the previous publications on the ${ }^{31} \mathrm{P}$ NMR of melamine phosphate. ${ }^{32,33}$

\subsection{2}

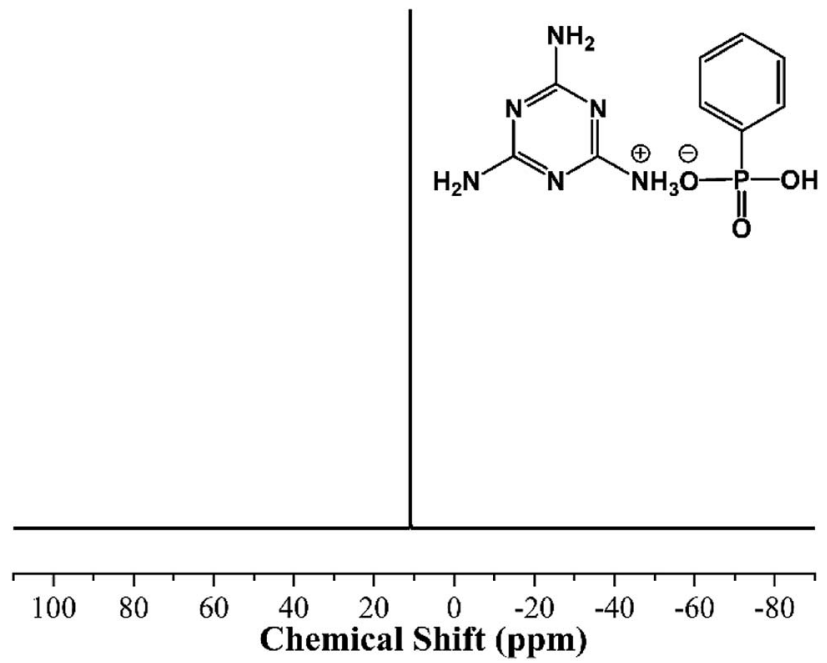

Fig. $4{ }^{31} \mathrm{P}$ NMR of MPhP. 


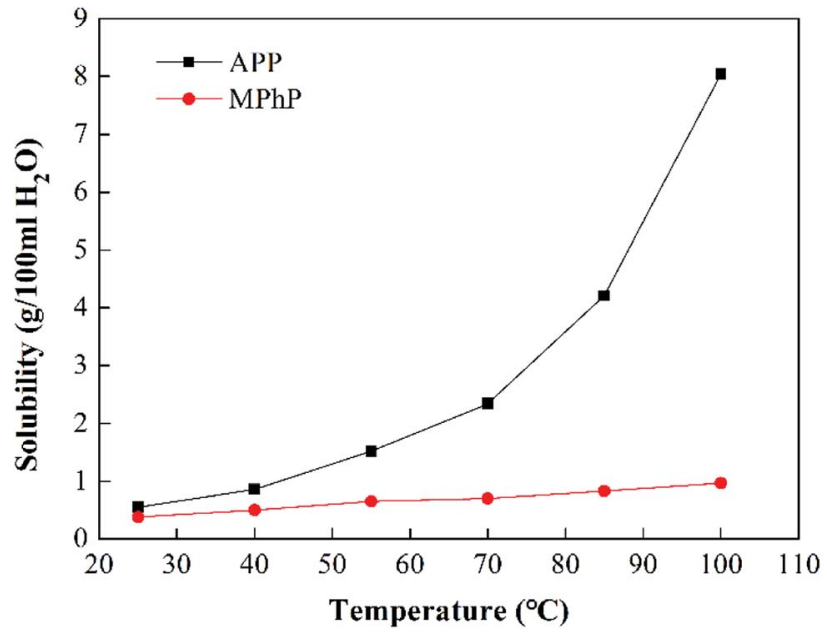

Fig. 5 Solubility of MPhP and APP in water at different temperatures.

Water resistance. The water solubility of MPhP at different temperatures is shown in Fig. 5. The solubility of MPhP at $25{ }^{\circ} \mathrm{C}$ is $0.38 \mathrm{~g} / 100 \mathrm{ml} \mathrm{H}_{2} \mathrm{O}$. The solubility of MPhP increases slowly with an increase in the temperature. The solubility of MPhP at $100{ }^{\circ} \mathrm{C}$ is only $0.97 \mathrm{~g} / 100 \mathrm{ml} \mathrm{H}_{2} \mathrm{O}$. For comparison, the water solubility of APP at different temperatures is also shown in Fig. 5. The solubility of APP at $25{ }^{\circ} \mathrm{C}$ and $100{ }^{\circ} \mathrm{C}$ is $0.55 \mathrm{~g} / 100 \mathrm{ml}$ $\mathrm{H}_{2} \mathrm{O}$ and $8.04 \mathrm{~g} / 100 \mathrm{ml} \mathrm{H}_{2} \mathrm{O}$, respectively. It is clearly seen that the solubility of APP increases greatly with an increase in the temperature, indicating that APP is easily attacked by hot water. ${ }^{19}$ Compared with APP, MPhP has lower water solubility especially at high temperatures. The low water solubility may be due to the presence of triazine rings and benzene rings in MPhP increases the steric hindrance, which makes MPhP less likely to form hydrogen bonds with water and less susceptible to water attack. $^{34}$

\section{Effect of MPhP on flame retardancy of the EP/MPhP composites}

The flame retardancy of the EP/MPhP composites was characterized by limiting oxygen index (LOI) and UL-94 vertical burning test, and the test results are listed in Table 2. The LOI of pure EP is $20.5 \%$. The LOI values of the EP/MPhP composites increase with an increase in the MPhP content. When the loading of MPhP is $20 \mathrm{wt} \%$ and $25 \mathrm{wt} \%$, the LOI values of the EP/MPhP composites (samples EP/MPhP20 and EP/MPhP25) reach to $26.5 \%$ and $27.5 \%$, respectively. Moreover, both sample EP/MPhP20 and sample EP/MPhP25 pass the UL-94 V0 rating. The flame retardant mechanism of MPhP in EP may

Table $2 \mathrm{LOI}$ and UL-94 results of the EP/MPhP composites

\begin{tabular}{llc}
\hline Sample & LOI $(\%)$ & UL-94 \\
\hline EP0 & 20.5 & NR \\
EP/MPhP5 & 22.5 & NR \\
EP/MPhP10 & 23.5 & NR \\
EP/MPhP15 & 24.5 & V-1 \\
EP/MPhP20 & 26.5 & V-0 \\
EP/MPhP25 & 27.5 & V-0
\end{tabular}

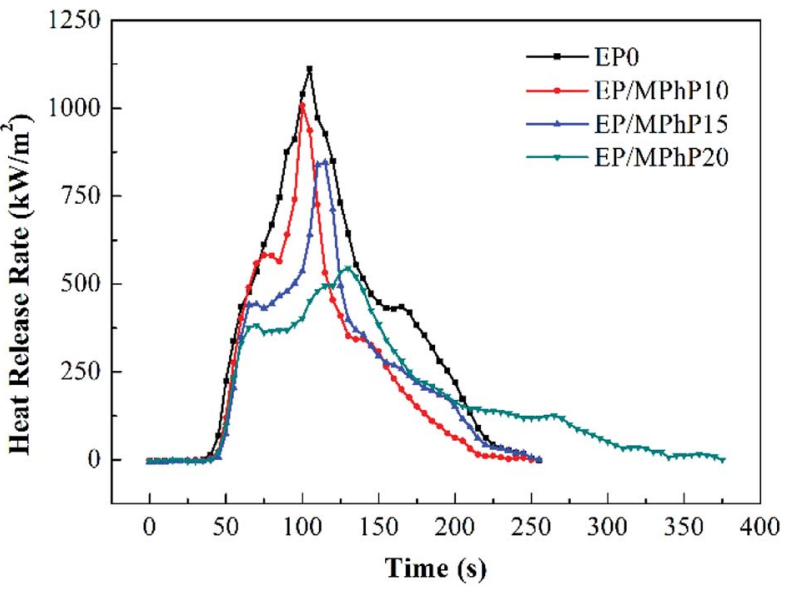

Fig. 6 HRR curves of pure EP and the EP/MPhP composites in the CC test.

be due to the following two aspects. On one hand, MPhP decomposes on heating to form non-combustible gases such as $\mathrm{N}_{2}$ and $\mathrm{NH}_{3}$, which dilute the combustible gases and oxygen in the gas phase. On the other hand, the phosphorus-containing acids generated during the decomposition of MPhP promote EP to form carbonaceous char. ${ }^{17,35}$

Cone calorimeter (CC) is a very useful method to study the combustion behavior of flame retardant polymers. ${ }^{36}$ Heat release rate (HRR), characterized by heat release at per unit surface area of burning materials has a great influence on fire hazard..$^{37}$ HRR curves of pure EP resin and the EP/MPhP composites are shown in Fig. 6. Peak HRR (PHRR) of pure EP resin is about $1111 \mathrm{~kW} \mathrm{~m}^{-2}$. The PHRR values of the $\mathrm{EP} / \mathrm{MPhP}$ composites decrease with an increase in the MPhP content. For example, the PHRR values of the EP/MPhP composites with $15 \%$ and $20 \%$ MPhP decrease by $24 \%$ and $51 \%$, respectively. Total heat release (THR) curves of pure EP resin and the EP/ MPhP composites are shown in Fig. 7. And THR values of the $\mathrm{EP} / \mathrm{MPhP}$ composites also decrease compared with the one of the pure resin. Moreover, the time to ignition (TTI) of the EP/ MPhP composites is all higher than that of the pure resin,

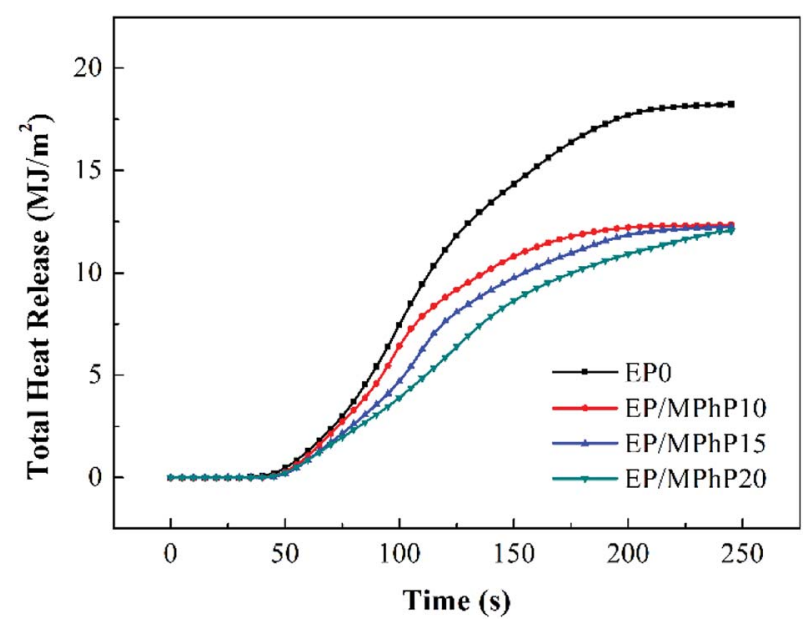

Fig. 7 THR curves of pure EP and the EP/MPhP composites in the CC test. 
Table 3 Cone calorimeter data of pure EP and the EP/MPhP composites

\begin{tabular}{lcccc}
\hline Sample code & TTI $^{a}(\mathrm{~s})$ & PHRR $\left(\mathrm{kW} \mathrm{m}^{-2}\right)$ & THR $\left(\mathrm{MJ} \mathrm{m}^{-2}\right)$ & $18.2 \pm 0.3$ \\
EP0 & 32 & $1111 \pm 50$ & $12.4 \pm 0.3$ & $3457 \pm 300$ \\
EP/MPhP10 & 38 & $1008 \pm 50$ & $12.2 \pm 0.3$ & $2901 \pm 300$ \\
EP/MPhP15 & 40 & $846 \pm 50$ & $12.0 \pm 0.3$ & $2640 \pm 300$ \\
EP/MPhP20 & 41 & $545 \pm 50$ &
\end{tabular}

${ }^{a}$ TTI: Time to ignition; PHRR: peak of heat release rate; THR: total heat release; TSR: total smoke release.
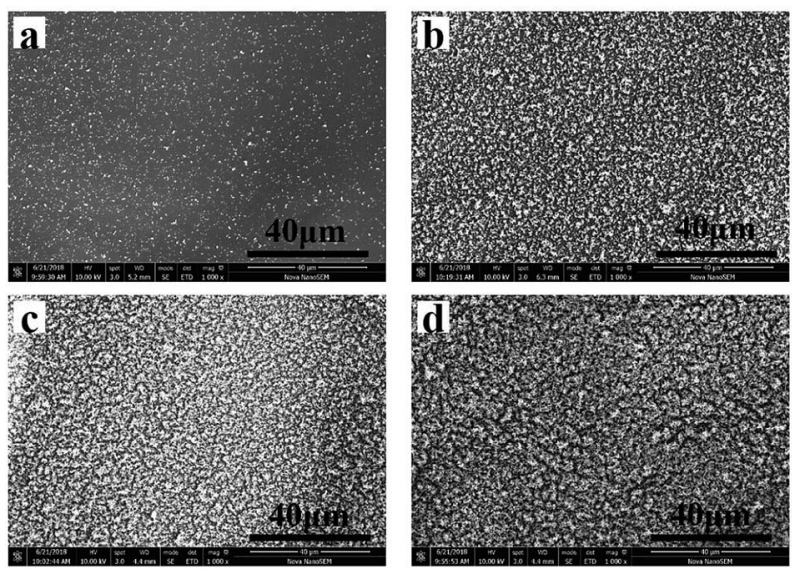

Fig. 8 SEM micrographs of the residue chars after the CC test: (a) EPO; (b) EP/MPhP10; (c) EP/MPhP15; (d) EP/MPhP20.

which indicates that the combustion of the EP/MPhP composites is prolonged in comparison with pure EP resin. As for smoke release during the combustion, it is seen from the Table 3 that total smoke release (TSR) of the EP/MPhP composites decreases with an increase in the MPhP loading. From Fig. 6, it can be found that pure EP resin has one HRR peak, while the EP/MPhP composites burn with two HRR peaks, which is similar to some intumescent flame retardant systems. ${ }^{38-41}$ The first peak is usually caused by the combustion of polymer resins, and the second peak may be due to the further cracking and effective pyrolysis of formed char. ${ }^{42}$

The SEM images of the residues of pure EP and the EP/MPhP composites are shown in Fig. 8. From Fig. 8a, it can be seen that there are only few char crumbs on the surface of the char layers and the char crumbs are non-continuous. When MPhP is added into the EP resin, the char becomes thicker and more compact with the increase in the MPhP content (from Fig. $8 \mathrm{~b}$ to d). The compact char layers can form protective shields on the surface of EP composites to limit the transfer of heat and flammable compounds. ${ }^{16}$ Therefore, the PHRR, THR and TSR values of the $\mathrm{EP} / \mathrm{MPhP}$ composites are reduced.

\section{Water resistance of the EP/MPhP composites}

In order to investigate water resistance of the $\mathrm{EP} / \mathrm{MPhP}$ composites, samples of the composites were immersed into hot water at $80^{\circ} \mathrm{C}$ for $72 \mathrm{~h}$. The LOI values and UL-94 ratings of the samples after the water treatment are listed in Table 4 . It can be seen from Table 4 that the LOI values of the EP/MPhP composites after the treatment changed little compared with
Table $4 \mathrm{LOI}$ and UL-94 test results of the EP/MPhP composites after water treatment $\left(80^{\circ} \mathrm{C}, 72 \mathrm{~h}\right)$

\begin{tabular}{lll}
\hline Sample & LOI $(\%)$ & UL-94 \\
\hline EP0 & 20.5 & NR \\
EP/MPhP5 & 22.0 & NR \\
EP/MPhP10 & 23.5 & NR \\
EP/MPhP15 & 24.0 & V-1 \\
EP/MPhP20 & 26.5 & V-0 \\
EP/MPhP25 & 27.5 & V-0
\end{tabular}

the values of the corresponding untreated composites (Table 2). Moreover, UL-94 test results of the EP/MPhP composites before and after the treatment are the same. The above results indicate that the water treatment has little influence on the flame retardancy of the EP/MPhP composites.

SEM was used to study the surface fracture of pure EP resin (EP0) and the EP/MPhP20 composite after the hot water treatment, and its micrographs are shown in Fig. 9. As for pure EP resin, a smooth fracture surface with river-like lines can be observed (Fig. 9a), which shows a typical characteristic of brittle fracture. ${ }^{43}$ The fracture surface of pure EP after the treatment (Fig. 9b) remains the same, indicating that epoxy resin itself has good water resistance. It is due to the high crosslinking degree of the resin, which leads to a good sealing property and makes it less susceptible to water erosion. ${ }^{44}$ The fracture surface of the untreated EP/MPhP20 composite (Fig. 9c) is much rougher compared with EP0, and the cracks are tortuous and
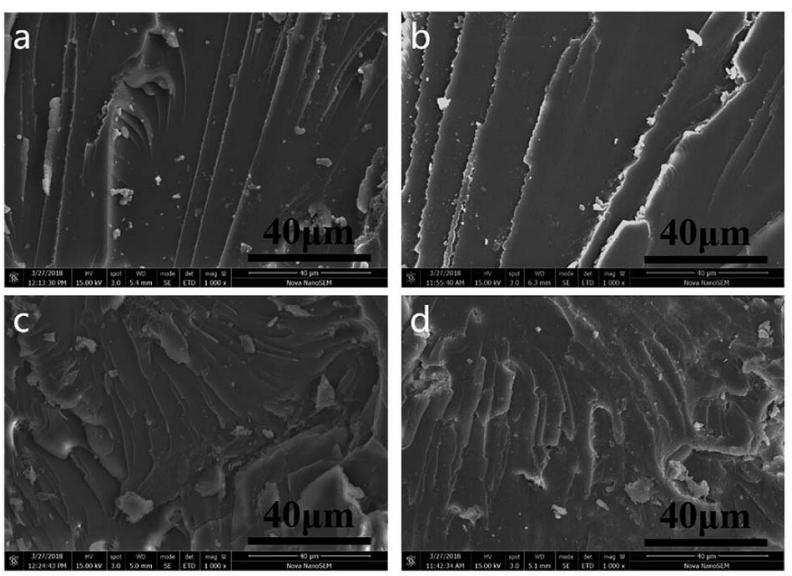

Fig. 9 SEM micrographs of fracture surfaces: (a) pure EP; (b) pure EP (treated in $80{ }^{\circ} \mathrm{C}$ water for $72 \mathrm{~h}$ ); (c) EP/MPhP20; (d) EP/MPhP20 (treated in $80^{\circ} \mathrm{C}$ water for $72 \mathrm{~h}$ ). 


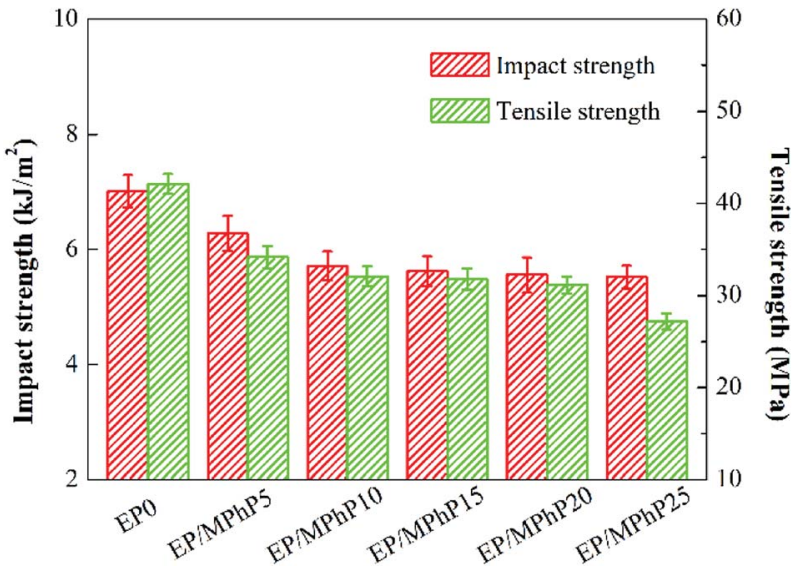

Fig. 10 Impact and tensile strengths of pure EP and the EP/MPhP composites.

nonlinear. ${ }^{45}$ It can be seen that some MPhP particles are located onto the fracture surface of the composite. The result suggests that the addition of MPhP changes the stress distribution and leads to local stress concentration during stress, resulting in disturbing the oriented fracture patterns of epoxy. This phenomenon was observed in some other publications. ${ }^{21}$ The morphology of the treated EP/MPhP20 composite (Fig. 9d) is quite similar to the one of the untreated EP/MPhP20 composite. After the water treatment, the MPhP particles are still on the fracture surface of the composite, indicating that the EP/MPhP composite has good resistance of water, which may be due to the existence of $\mathrm{P}-\mathrm{C}$ bonds in MPhP: the $\mathrm{P}-\mathrm{C}$ bonds are hydrolysis resistant, and thus they reduce the influence of water in some aspects. ${ }^{46}$

\section{Effect of MPhP on mechanical properties of the EP/MPhP composites}

Fig. 10 shows the impact and tensile strengths of pure EP and the EP/MPhP composites. The impact and tensile strengths of pure EP is $7.0 \mathrm{~kJ} \mathrm{~m}^{-2}$ and $42.1 \mathrm{MPa}$, respectively. The strengths of the EP/MPhP composites decrease gradually with an increase in the MPhP content. For example, the impact strength and the tensile strength of EP/MPhP20 composite decrease $20.7 \%$ and

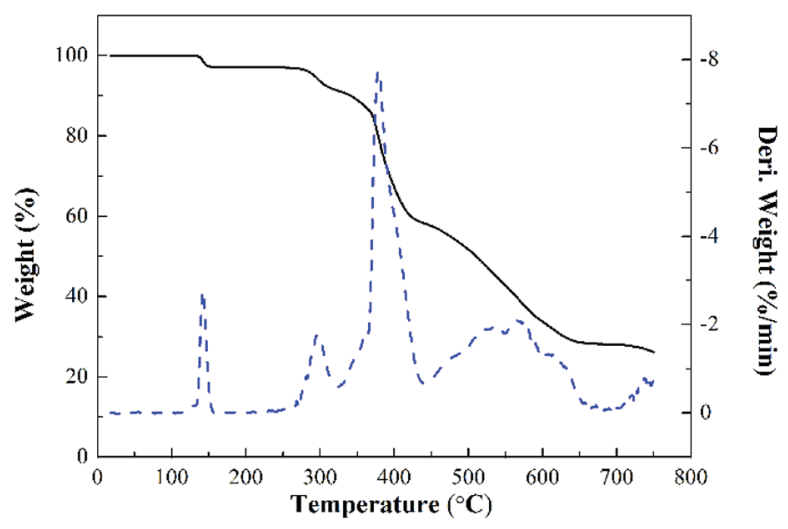

Fig. 11 TG and DTG curves of MPhP under nitrogen atmosphere.
$26.0 \%$, respectively compared with those of pure EP. The decrease of the mechanical strengths is possibly due to the weak interfacial interaction between MPhP particles and EP matrix, which makes the particles easy to be separated at the interface under external force. ${ }^{47}$ Moreover, the viscosity of EP composites increases with the increase of MPhP content, and thus the particles cannot be evenly dispersed in EP matrix, causing obvious stress concentration in the EP/MPhP composites, which results in a decrease in the mechanical properties of the EP/MPhP composites under the external force. ${ }^{48}$

\section{Thermal decomposition of the EP/MPhP composites}

Fig. 11 shows the TG and DTG curves of MPhP. It can be seen from DTG curve that MPhP has four distinctive decomposition stages. The first stage occurs between $140{ }^{\circ} \mathrm{C}$ and $160{ }^{\circ} \mathrm{C}$, and the weight loss is approximately $2.9 \%$, which may be due to the evaporation of bound water. The second stage occurring in the range $270-320{ }^{\circ} \mathrm{C}$ with a weight loss of $5.5 \%$, which may be caused by the dehydration and deamination of the hydroxyl groups to form polyphosphates. ${ }^{49}$ As the temperature continues to increase, the decomposition of MPhP enters into the third stage. The maximum weight loss temperature is $378^{\circ} \mathrm{C}$, and the weight loss at this stage is about $22.7 \%$. The main reason for the weight loss is due to the decomposition of the melamine's structure in MPhP molecules producing $\mathrm{N}_{2}$ and $\mathrm{NH}_{3}$. At the temperature above $450{ }^{\circ} \mathrm{C}$, the phosphorus and nitrogen compounds produced at previous stages decompose further to form aromatic compounds. ${ }^{50}$

Fig. 12 and 13 show the TG and DTG curves of pure EP and the EP/MPhP composites. The temperature of $10 \%$ weight loss $\left(T_{10 \%}\right)$, the mid-point temperature of the degradation $\left(T_{50 \%}\right)$, the temperature at the maximal weight loss rate $\left(T_{\max }\right)$, and the weight of residue at $750{ }^{\circ} \mathrm{C}$ are summarized in Table 5. Pure EP has two steps of degradation under nitrogen atmosphere. ${ }^{51,52}$ The first step occurs before $300{ }^{\circ} \mathrm{C}$, and the degradation is due to the elimination of hydrated water. The second step happens in the range $300-500{ }^{\circ} \mathrm{C}$ with a $T_{\max }$ of $367^{\circ} \mathrm{C}$, and the weight

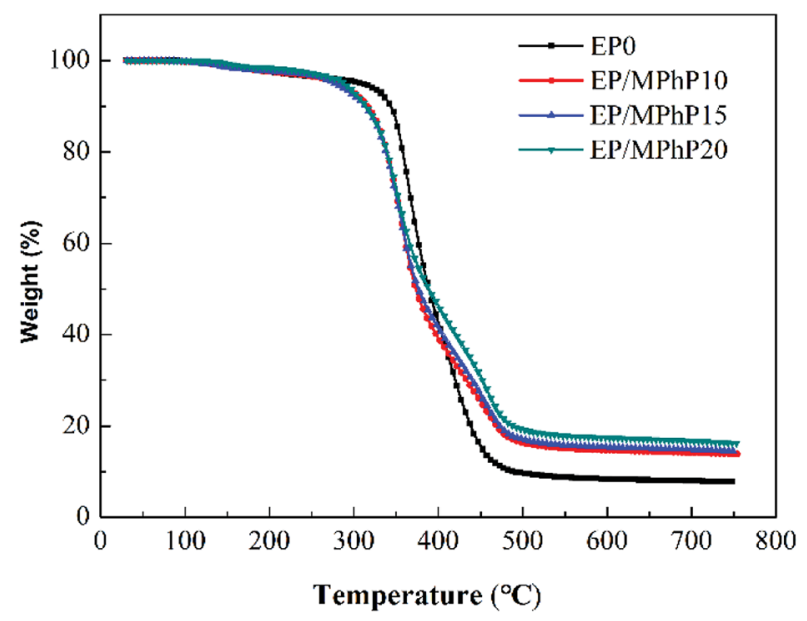

Fig. 12 TG curves of pure EP and the EP/MPhP composites under nitrogen atmosphere. 


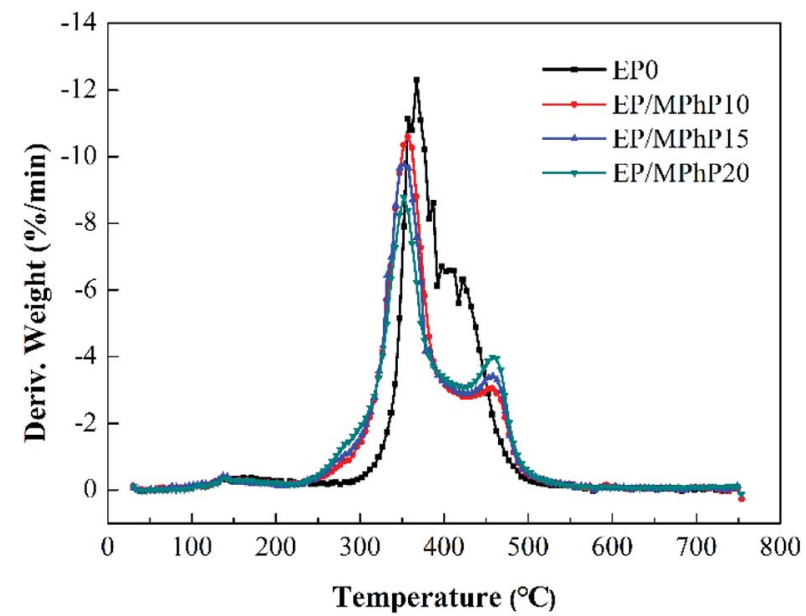

Fig. 13 DTG curves of pure EP and the EP/MPhP composites under nitrogen atmosphere.

Table 5 TG data of pure EP and the EP/MPhP composites

\begin{tabular}{llllc}
\hline Sample & $T_{10 \%}\left({ }^{\circ} \mathrm{C}\right)$ & $T_{50 \%}\left({ }^{\circ} \mathrm{C}\right)$ & $T_{\max }\left({ }^{\circ} \mathrm{C}\right)$ & $\begin{array}{c}\text { Residue at } \\
750{ }^{\circ} \mathrm{C}(\%)\end{array}$ \\
\hline EP0 & 342 & 388 & 367 & 7.8 \\
EP/MPhP10 & 313 & 371 & 357 & 13.9 \\
EP/MPhP15 & 313 & 374 & 353 & 14.5 \\
EP/MPhP20 & 313 & 387 & 352 & 16.2 \\
\hline
\end{tabular}

loss is $30.1 \%$, which is caused by the chain scission of isopropylidene linkages releasing small molecule products. ${ }^{15}$

The degradation of the EP/MPhP composites has two steps. Compared with pure EP, the EP/MPhP composites decompose earlier at lower temperatures, which is mainly due to the decomposition of MPhP. Although $T_{10 \%}, T_{50 \%}$, and $T_{\max }$ of the $\mathrm{EP} / \mathrm{MPhP}$ composites are lower than the values of pure EP resin, the rates of the decomposition of the EP/MPhP composites slow down in the range $400-500{ }^{\circ} \mathrm{C}$, and the residue left at $750{ }^{\circ} \mathrm{C}$ increases significantly. The weight of residue at $750{ }^{\circ} \mathrm{C}$ for $\mathrm{EP} /$ MPhP20 is $16.2 \%$, which is about 2 times higher than that of EP.

\section{Conclusions}

In this paper, a flame retardant melamine phenylphosphate (MPhP) was successfully synthesized, and characterized by FTIR and NMR. MPhP has a lower water solubility compared with the commonly used APP. The effect of MPhP on flame retardancy, mechanical properties and water resistance of epoxy resin (EP) was investigated. The LOI values of the EP/MPhP composite increase with an increase in the MPhP content. The LOI of the EP composite containing $20 \mathrm{wt} \% \mathrm{MPhP}$ (EP/MPhP20) is $26.5 \%$, and the EP composite reaches to UL $94 \mathrm{~V}-0$ rating. The LOI values of the $\mathrm{EP} / \mathrm{MPhP}$ composites after the water treatment at $80^{\circ} \mathrm{C}$ for $72 \mathrm{~h}$ are basically unchanged, and the UL 94 ratings are still maintained. The peak heat release rate, total heat release and total smoke release of $\mathrm{EP} / \mathrm{MPhP} 20$ decrease by $51 \%, 34 \%$, and $24 \%$, respectively compared with those of pure EP. The impact and tensile strengths of the EP/MPhP composites decrease with an increase in the MPhP content. The incorporation of MPhP into EP leads to a decrease in the initial decomposition temperature and an increase in the residue at high temperatures.

\section{Conflicts of interest}

There are no conflicts to declare.

\section{Acknowledgements}

This work was financially supported by the National Natural Science Foundation of China (21174106).

\section{References}

1 F. Xiao, K. Wu, F. B. Luo, Y. Y. Guo, S. H. Zhang, X. X. Du, Q. Q. Zhu and M. G. Lu, J. Mater. Sci., 2017, 52, 13992-14003. 2 J. l. Zhuo, L. B. Xie, G. D. Liu, X. L. Chen and Y. G. Wang, J. Therm. Anal. Calorim., 2017, 129, 357-366.

3 W. Wang, Y. C. Kan, Y. Pan, Y. Yuan, L. M. Liew and Y. Hu, Ind. Eng. Chem. Res., 2016, 56, 1341-1348.

4 Y. Wang, C. Yang, Q. X. Pei and Y. Zhang, ACS Appl. Mater. Interfaces, 2016, 8, 8272-8279.

5 Y. Xu, Y. Li, W. Hua, A. Zhang and J. Bao, ACS Appl. Mater. Interfaces, 2016, 8, 24131-24142.

6 X. M. Wen, B. G. Li and Y. L. Yin, Tianjin Chem. Ind., 2013, 27, $1-4$.

7 Y. X. Ou, X. M. Fang and Q. Shen, Fine Chem., 2007, 24, 12321235.

8 R. K. Jian, P. Wang, W. Duan, J. S. Wang, X. L. Zheng and J. B. Weng, Ind. Eng. Chem. Res., 2016, 55, 11520-11527.

9 P. Müller, M. Morys, A. Sut, C. Jäger, B. Illerhaus and B. Schartel, Polym. Degrad. Stab., 2016, 130, 307-319.

10 Q. Hu, P. R. Peng, S. Peng, J. Y. Liu, X. Q. Liu, L. Y. Zou and J. Chen, J. Therm. Anal. Calorim., 2016, 128, 1-10.

11 B. Perret, B. Scharte, K. Stöß, M. Ciesielski, J. Diederichs, M. Döring, J. Krämer and V. Altstädt, Eur. Polym. J., 2011, 47, 1081-1089.

12 L. Qian, Y. Qiu and N. Sun, Polym. Degrad. Stab., 2014, 107, 98-105.

13 W. Zhang, X. Li and R. Yang, Polym. Degrad. Stab., 2014, 99, 118-126.

14 W. Yan, J. Yu, M. Q. Zhang, T. Wan, C. Z. Wen, S. H. Qin and W. J. Huang, J. Polym. Res., 2018, 25, 72.

15 X. Wang, Y. Hu, L. Song, W. Y. Xing, H. D. Lu, P. Lv and G. X. Jie, Polymer, 2010, 51, 435-2445.

16 J. Wang, D. Wang, Y. Liu, X. Ge and Y. Wang, J. Appl. Polym. Sci., 2008, 108, 2644-2653.

17 Y. Tan, Z. B. Shao, L. X. Yu, J. W. Long, M. Qi, L. Chen and Y. Z. Wang, Polym. Chem., 2016, 7, 3003-3012.

18 L. Song, K. Wu, Y. Wang, Z. Z. Wang and Y. Hu, J. Macromol. Sci., Part A: Pure Appl.Chem., 2009, 46, 290-295.

19 K. Wu, Z. Z. Wang and Y. Hu, Polym. Adv. Technol., 2010, 19, 1118-1125. 
20 L. Liu, Y. N. Zhang, L. Li and Z. Z. Wang, Polym. Adv. Technol., 2011, 22, 2403-2408.

21 Q. Tang, B. Wang, Y. Shi, L. Song and Y. Hu, Ind. Eng. Chem. Res., 2013, 52, 5640-5647.

22 Z. J. Zhang, X. J. Mei and L. R. Feng, Chin. J. Appl. Chem., 2003, 20, 1035-1038.

23 R. B. Wang, Z. X. Ge, Z. L. Yao and H. L. Liu, Appl. Chem. Ind., 2009, 38, 1826-1827.

24 P. M. Wang and Q. W. Xu, Material Research Methods, Science Press, Beijing, 2010.

25 S. Mahmoud, E. Bassam, N. D. Jamal, S. Amneh, K. Monther and E. Mohammad, Phosphorus Sulfur Silicon Relat. Elem., 2014, 189, 558-575.

26 Z. Wahab, E. A. Foley, P. J. Pellechia, B. L. Anneaux and H. J. Ploehn, J. Colloid Interface Sci., 2015, 450, 301-309.

27 H. Nijs, A. Clearfield and E. F. Vansant, Microporous Mesoporous Mater., 1998, 23, 97-110.

28 J. Svoboda, V. Zima, L. Beneš, K. Melánová, M. Vlček and M. Trchová, J. Phys. Chem. Solids, 2008, 69, 1439-1443.

29 L. Costa and G. Camino, J. Therm. Anal., 1988, 34, 423-429. 30 S. Gao and G. Liu, J. Appl. Polym. Sci., 2018, 135, 46274.

31 R. H. Ye, Y. Chen, Y. L. Liu, L. M. Zhu, Z. Q. Li, Y. F. Sun and W. L. Pan, J. Instrum. Anal., 2011, 30, 624-628.

32 S. Jahromi, w. Gabriëlse and A. Braam, Polymer, 2003, 44, 2537.

33 X. M. Fu, Y. Liu, Q. Wang, Z. J. Zhang, Z. Y. Wang and J. Y. Zhang, J. Macromol. Sci. Part D Rev. Polym. Process., 2011, 50, 1527-1532.

34 W. Chen, L. Wang and G. Liu, Polym. Degrad. Stab., 2012, 97, 2567-2570.

35 B. Schartel, A. Weiß, F. Mohr, M. Kleemeier and A. Hartwig, J. Appl. Polym. Sci., 2010, 118, 1134-1143.
36 M. L. Bras, M. Bugajny, J. Lefebvre and S. Bourbigot, Polym. Int., 2015, 49, 1115-1124.

37 Y. Liu Y, C. L. Deng, J. Zhao, J. S. Wang, L. Chen and Y. Z. Wang, Polym. Degrad. Stab., 2011, 96, 363-370.

38 S. Bourbigot, M. L. Bras, S. Duquesne and M. Rochery, Macromol. Mater. Eng., 2004, 289, 499-511.

39 M. J. Chen, X. Wang, X. L. Li, X. Y. Liu, L. Zhong, H. Z. Wang and Z. G. Liu, RSC Adv., 2017, 7, 35619-35628.

40 J. S. Wang, Y. Liu, H. B. Zhao, J. Liu, D. Y. Wang, Y. P. Song and Y. Z. Wang, Polym. Degrad. Stab., 2009, 94, 625-631.

41 C. Ma, B. Yu, N. Hong, Y. Pan and W. Hu, Ind. Eng. Chem. Res., 2016, 55, 10868-10879.

42 B. Schartel and T. R. Hull, Fire Mater., 2010, 31, 327-354.

43 M. Naderi, M. Hoseinabadi, M. Najafi, S. Motahari and M. Shokri, J. Appl. Polym. Sci., 2018, 135, 46201.

44 J. Ding, Int. J. Electrochem. Sci., 2016, 11, 6256-6265.

45 J. Ding, O. U. Rahman, W. Peng, H. Dou and H. Yu, Appl. Surf. Sci., 2018, 427, 981-991.

46 J. W. Yang and Z. Z. Wang, Fire Mater., 2018, 5, 1-7.

47 C. G. H. Manjunatha, J. Mater. Environ. Sci., 2017, 8, 16611667.

48 L. G. Lu, Y. H. Chen, Z. Cheng, S. S. Yang and G. S. Shao, J. Mater. Sci. Eng., 2015, 43, 50-55.

49 X. Y. Li, Z. Z. Wang and H. J. Liang, Polym. Mater. Sci. Eng., 2007, 23, 145-148.

50 C. Breen, N. D'Mello and J. Yarwood, J. Mater. Chem., 2002, 12, 273-278.

51 X. Wang, Y. Hu, L. Song, W. Xing and H. Lu, J. Polym. Sci., Part B: Polym. Phys., 2010, 48, 693-705.

52 X. B. Wang and S. S. Yang, Plast. Sci. Technol., 2010, 38, 4749. 